\title{
Sexual Harassment among University Students within University of Eldoret, Uasin Gishu County, Kenya.
}

\author{
R. K. A. Sang ${ }^{1}$,J. K. Kemboi ${ }^{2}$,R. O. Omenge. ${ }^{1}$
}

\begin{abstract}
Sexual harassment (SH) has been defined asa non-consensual and unwelcome sexual behaviour that affects lives of the victims.Approximately 50\% of all women in the United States at some time or other experiencesome type of sexual harassment, either in the workplace or in academic environments. SH has been identified as the most frequent form of "sexual victimization" and as a category of violence against women. SH has also been described as a form of social control exerted by men to "keep women in their place." The Fourth World Conference on Women (FWCW) Beijing Declaration (UN documents, 2004) included SH in its category of "physical, sexual, and psychological" violence against women. This study which adopted a purposive descriptive research design involving 100 University of Eldoretstudents whose data was collected using questionnaires and interview schedules revealed that about half of the interviewed students had experienced various forms of sexual harassment without their consent. The harassments included rude sexual jokes, showing/passing pornographic materials, indecent gestures, attitudes, behaviours, insults and touches resulting in discrimination against the victims by violating their rights physiologically, sexually and physically. Like many other institutions of Higher Learning, University of Eldoret has no policy guidelines to assist institution managers in handling sexual harassment issues.
\end{abstract}

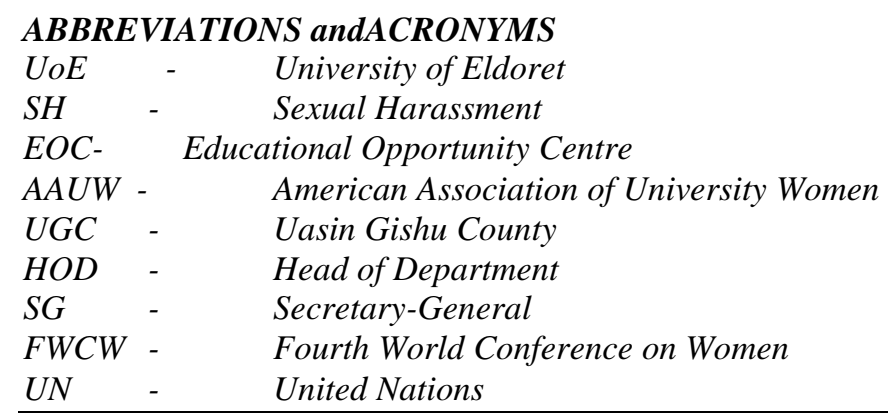

\section{Introduction}

The American Association of University Women (AAUW) defines $\mathrm{SH}$ as a non-consensual and unwelcome sexual behavior that affects lives of the victims. This definition emphasizes the consequences and implications of sexual harassment, and distinguishes it from consensual behaviors such as flirting, kissing and touching. Forms of SH vary a lot, which transverse from one end of physical sexual assault to the other end of the non-verbal sex cues. In the era of information explosion today, internet and related social networking enhance the occurrence of SH due to the fact that harassers can rapidly abuse others anonymously without restriction in a specific physical locale. Commonly, they believe that they will not be liable to legal responsibilities.

Fitzgerald (1993), in a landmark article, stated that approximately 50\% of all women in the United States at some time would experience a type of sexual harassment $(\mathrm{SH})$, either in the workplace or in academic environments. The Fourth World Conference on Women (FWCW) Beijing Declaration (UN documents, 2004) included SH in its category of "physical, sexual, and psychological" violence against women. There are many grey areas regarding $\mathrm{SH}$ perceived by adolescent peers.

Most SH is perpetrated by male students against female students. However, there are also cases of harassment by women against men, and of same sex harassment perpetrated by either sex. Other than campus environment, $\mathrm{SH}$ is common at every stage of education. $\mathrm{SH}$ on campus commonly occurs among peers and most students who experience it do not report what has happened. The dynamics of SH often involve an aggressor who holds a position of power over the victim, which include men against women, senior students against junior students, and in a teacher-student relationship. Moreover, those sexually harassed students can be targeted for retaliation if they report the cases, by both their peers and school employees.

\footnotetext{
${ }^{1}$ Egerton University ( Faculty of Health Sciences)

${ }^{2}$ Moi Teaching and Referral Hospital ( Clinical Services)

DOI: 10.9790/0853-150807142151 $\quad$ www.iosrjournals.org $\quad 142 \mid$ Page
}




\subsection{Statement of the Problem}

There are many grey areas regarding $\mathrm{SH}$ as perceived by adolescent peers in institutions of higher learning such as universities. Students of UoE feel dissatisfied and de-motivated due to what seems to be escalating activities related to sexual harassment among students.There is no data on the level of sexual harassment among students of Eldoret University.

\subsection{Justification}

University of Eldoret (UoE) like other public institutions of higher learning and being a public institution mandated with the regional development operates through policies as stipulated by the government. The governments' policies do not give room for issues related to students' sexual harassment. UoE has not evaluated students' sexual attitudes and their views on SH since it does not have a policy on sexual harassment. The findings of this study will help in informing the institution in putting in place appropriate policies that will guide in handling issues related to sexual harassment.

\subsection{Objectives of Study}

\subsubsection{Main Objective}

To determine the prevalence of sexual harassment among university students within University of Eldoret.

\subsubsection{Specific Objectives}

i. To determine the level of sexual harassment among university students within the institution.

ii. To establish knowledge and experiences of any form of sexual harassment among university students within University of Eldoret.

iii. To establish the perception and attitude of university management towards students' sexual harassment

iv. To establish the effects of sexual harassment on students' academic performance at the institution.

\subsection{Research Questions}

The research addressed the following questions;

i. What is the extent of sexual harassment among university students within the institution?

ii. Do students have knowledge and experiences of any form of sexual harassmentamong them within the institution?

iii. What is the perception and attitude of university management towards students' sexual harassment within University of Eldoret?

iv. What are the effects of SH to students' academic performance at the University?

\subsection{Significance of the Study}

This study comesat a time when students of UoE feel dissatisfied and de-motivated due to what seems to be escalating activities related to sexual harassment among students. The findings of the study will therefore be handy in taming excesses on sexual harassment and therefore promote gender equality so as to realize high academic performance among students. The research will come up with recommendations on appropriate policies that will guide and inform appropriate management strategies on sexual harassment in the entire institution which can also be replicated in other institutions country-wide. The envisaged new management will increase institution's productivity, reduce stress, absenteeism and overall students' academic performance and promote a peaceful university environment conducive for learning.

\subsection{LITERATURE REVIEW}

\subsubsection{Introduction}

The literature was reviewed from books, articles, general periodicals, journals, internet information and research works.

\subsubsection{Sexual Harassment \\ 1.7.2.1 Sexual Harassment Globally}

Fitzgerald (1993), in a landmark article, stated that approximately $50 \%$ of all women in the United States at some time would experience a type of sexual harassment, either in the workplace or in academic environments. In her article, Fitzgerald identified SH as the most frequent form of "sexual victimization" and as a category of violence against women. SH also was described as a form of social control exerted by men to "keep women in their place." Similarly, in an international context, the Fourth World Conference on Women (FWCW) Beijing Declaration (UN documents, 2004) included SH in its category of "physical, sexual, and psychological" violence against women. There are many grey areas regarding SH perceived by adolescent peers. 
They are mostly presumed as normal teenage behavioursin order to experience what gender is, and to explore the development of gender roles (Margolis, 1993). Therefore, prior to what "sexual harassment" means, it is essential to differentiate any welcomed, two-way, mutually agreed and interactive sex-related behaviours, flirts, attraction and friendship, which should not be considered as SH (Dellinger \& Williams, 2002; Williams et al., 1999).

The European Union (EU) and the Council of Europe (COE) have developed policies and directives against sexual harassment, which are translated into "legally binding law" in individual countries. Both organizations describe SH as sex discrimination, which interferes with a person's "right to dignity in the workplace." EU countries which are subjected to these directives include:Austria, Belgium, Cyprus, the Czech Republic, Denmark, Estonia, Finland, France, Germany, Greece, Hungary, Ireland, Italy, Latvia, Lithuania, Luxembourg, Malta, the Netherlands, Poland, Portugal, Slovakia, Slovenia, Spain, Sweden, and the United Kingdom. The following countries are members of the $\mathrm{COE}$ and are required to implement these directives: Albania, Armenia, Azerbaijan, Bosnia and Herzegovina, Bulgaria, Croatia, the Czech Republic, Estonia, Georgia, Hungary, Latvia, Lithuania, Macedonia, Moldova, Poland, Romania, the Russian Federation, Serbia and Montenegro, Slovakia, Slovenia, and the Ukraine.

Since 1995, laws against SH have been established in Asia, Australia, Bangladesh, Japan, the Philippines, Sri Lanka, and Hong Kong, China. In India, the Supreme Court identified SH as a significant social problem and specified steps or guidelines to prevent SH (ILO, 2001). Brazil and other Latin American countries have signed the Inter-American Convention to Prevent, Punish and Extinguish Violence against Women (Trend Watcher, 2001).Apart from the fact that victims are subjected to SH involuntarily, it should also be noted that SH may be classified as verbal, physical and non-verbal categories (Timmerman, 2005), which transverse from one end of physical sexual assault to the other end of the non-verbal sex cues (Gutek et al., 2004). The American Association of University Women (AAUW) defines SH as a non-consensual and unwelcome sexual behaviour, which can affect lives of the victims. This definition emphasizes the consequences and implications of sexual harassment, and it distinguishes from consensual behaviours such as flirting, kissing and touching (AAUWEF, 2005).

\subsubsection{Sexual HarassmentRegionally}

\section{- South African Approach}

According to South African policy documents, Sexual attention becomes SH if:

i. The behaviour is persistent although a single incident of harassment can constitute sexualharassment; and/or

ii. The recipient has made it clear that the behaviour is considered offensive; and/or

iii. The perpetrator should have known that the behaviour is regarded as unacceptable.

The South African National Economic Development and Labour Council Code of Good Practices on the Handling of SH cases, Section 3, on interpretationof the definition of SH in order to determine whether SH has occurred, courts are allowed to apply subjective or objective standards. South African government guidelines suggest applying a subjective standard, using the viewpoint of the victim to determine whether a perpetrator's conduct amounts to sexual harassment. In the United States, courts apply both a subjective and objective standard. Courts determine whether conduct is $\mathrm{SH}$ based on how the victim views the conduct and whether a reasonable person in the same or similar circumstances would view the perpetrator's conduct as sexual harassment according to Deborah Zalesne on SH in the United States and South Africa: "Facilitating the Transition from Legal Standards to Social Norms”, Harvard Women's Law Journal, Vol. 25, 143, 164 (Spring 2002).

\section{- Sexual Harassment in Kenya}

Kenya is undergoing radical changes at national and local levels. All over the country, there is talk about the new Constitution of Kenya $(\mathrm{CoK})$ and its potential to usher in a new political and social order. While experience from other countries has precedents for this kind of optimistic discourse, there is need to undertake a more detailed analysis in order to understand the real benefits of these changes. In any case, there is no doubt more women have been getting access to formal employment and other relations of income in the last decade courtesy of progressive laws, affirmative action and their own competitiveness. The question, however, is whether these changes are yielding tangible improvements in both the condition and position of women workers. By condition, we mean change that improves the material well-being and overall worth of an individual. Verbal forms of change in position on the other hand means increased capability of an individual to enjoy their citizenship. At the workplace, this is often expressed through processes such as Collective Bargaining and the general ability of workers to express themselves or be heard as members of trade unions. 
One area that remains a major concern at the work place is the fact that women workers do not enjoy freedom over their bodies. Although there are men who often feel sexually harassed, it is women who tend to be most affected through actions that encompass: unwelcome sexual advances, demands for sexual favours and suggestive verbal or physical conduct where submission to, or rejection of, such advances affect the individual's employment status. These actions of affront to the woman's body and sexuality are often referred to as sexual harassment. They are broadly words or actions which are sexual in nature and which, inevitably, preclude someone from carrying out his or her work to the best of his or her ability.

While workers and employers know $\mathrm{SH}$ is inappropriate and unacceptable, it is extremely uncommon as a subject of litigation at the industrial court and does not feature during Collective Bargain negotiations. And, indeed, while SH is a problem that is universally faced by workers all over the world, women in lower rungs of work have to endure it more often. Worse still, at the work place, actions and remarks which demean and violate women have been normalized. These include verbal forms of SH through inappropriate jokes, sexual remarks and sexual teasing and touching. Demands or pressure for sexual favours constitute only a small percentage of complaints. At the same time, while employers and supervisors are culpable in any $\mathrm{SH}$ that takes place in the place of work, a majority of forms of harassment that tend to be normalized involve co-worker, rather than supervisory harassment. What workers want in the wake of numerous standards of legal accountability such as the Sexual Offences Act 2006, Constitution of Kenya 2010 and international discourse that disallow genderbased discrimination, it has become apparent that adequate information is now needed. To establish the trends of SH in Kenya, a study was conducted in Naivasha, Thika and Ruiru in 17 companies which differ in size, ownership, location, certification (or lack of it), unionized and not unionized. However, only in 15 farms did the management co-operate fully. A total of 35 women workers were interviewed, alongside seven male shop stewards and 15 trade unionists from different unions, two women managers and 13 women supervisors from 15 companies/farms. As many women find their way to the work place, employers have had to pay more attention to the subject of SH even if it is at the level of writing polices. However, just as has been the case with codes of practice, the trend tends to be toward rule compliance rather than ensuring that there is effective protection of women workers against harassment and discrimination at the workplace. Workers have often reported that employers still have much responsibility in ensuring that the work place is safe and promotes equity. To get our way out of this: there should be adequate provisions to punish employers where egregious harassment occurs under their watch; the Sexual Offences Act should permit individual supervisory liability for harassment, and employees and trade unions should consider SH as an agenda for their work place collective bargain negotiations.

Taken together, these changes might give employers the incentive to aim higher than mere compliance and towards success. In addition, it was suggested that some non-doctrinal efforts that may also contribute to the reduction or elimination of workplace harassment was to make it clear that $\mathrm{SH}$ is criminal such that the consequences for the perpetrator are so dire that one does not even dare think of it. Some of those interviewed included Steve Ouma who was Executive Director of Pamoja Trust and President of Labour Rights Centre and Eunice Muthoni who is SG and Coordinator of Workers Rights Watch.

\subsubsection{Types of Sexual Harassment}

The AAUW (2005) conducted a survey among college students and found that forms of SH involved sexual jokes; comments on body, look and private life; intentional touching of others; and sexual gestures or looks. More male students than female students were victims in some forms of sexual harassment. For example, $37 \%$ of the male students claimed that they were called homosexual, whereas $13 \%$ of the female students faced this type of verbal harassment. In general, researchers found that girls were more frequently harassed than boys (Young et al., 2008). SH was so common that when it happened, many girls did not become aware of its occurrence (Leaper \& Brown, 2008; Pepler et al., 2006). Although physical harassment was less frequent than verbal harassment, students who had experienced physical harassment were adversely affected (AAUWEF, 2001). Junior and senior secondary school students were often teased as homosexuals by their peers and the harassment brought negative influences on these teenagers under attack (GLSEN, 2005). Timmerman (2005) conducted a similar survey on students in Netherlands and found that most harassers were classmates rather than teaching staff. Some research works also revealed that most victims would not lodge complaints or inform relevant departments/agencies in response to (AAUWEF, 2011).

In relation to online sexual harassment, research findings showed that almost all the above group were connected to the Internet in some ways. Nowadays, there are diverse types of online and social media, including common social networking such as Facebook, Twitters, Google+ and MySpace; multi-media sharing such as YouTube, Flickr and Picasa; professional networking such as LinkedIn, Classroom2.0, Nurse Connect and SQL Monster; emails, SMS, and multi-functional modes of mobile phone comprising photo-taking, video-recording, WhatsApp, etc. All of the messages are transmitted away with great speeds. About $20-40 \%$ of students from first year to second year (ages-12-17) have experienced some forms of cyber bullying in the Internet and social 
networking (Tokunaga, 2010). Alarmingly, SH is regarded as a common phenomenon in cyber bullying (Shariff \& Strong-Wilson, 2005). Internet and related social networking enhance the occurrence of SH due to the fact that harassers can rapidly abuse others anonymously without restriction in a specific physical locale. Commonly, they believe that they will not be liable to legal responsibilities (Chaffin, 2008).

It is noteworthy that the local organization "Prevent Child Abuse" had conducted a survey in 2004 which revealed that in one month alone, $44 \%$ of the students received indecent and obscene messages online. Out of them, $79 \%$ deleted the obscene and indecent messages, but $8 \%$ would continue to browse and $6 \%$ would hesitate to browse or not. To deal with online sexual harassment, students had to face the issue alone by themselves. They seldom informed their parents $(21 \%)$ or friends $(19 \%)$.

\subsubsection{Limitation against Sexual Harassment}

There is specific legislation against SH in overseas countries or regions. The United States as early as 1964 included SH in the Human Rights Act. The Federal Supreme Court in 1986 regarded SH as a type of sex discrimination, of which exchange of interests and hostile work environment were identified. In Canada, SH is a crime and offenders will be prosecuted under "Sex Offences". In addition, Britain enacted the Equality Act 2010 and explained clearly harassment conducts (including sexual harassment) as discriminatory behaviours.

In Asia, Korea amended the Gender Equality Employment Act in early 1999 and defined SH as a crime. Directly under the president and designated with annual budget and personnel, the Ministry of Gender Equality was established in 2001. It is responsible for gender research, promotion of the Act, publicity of gender awareness and evaluation of implementation. Apart from Korea, Taiwan also has a comprehensive legal system specified for sexual harassment. There are the "Law for the Prevention of Sexual Harassment" and its implementation regulations, and the "Regulations of SH Meditation". Other than these, guidelines are designed for places where incidents of SH often happen, including the "Regulations on the Prevention of Sexual Assault or SH on Campus" and "Regulations for Establishing Measures of Prevention, Correction, Complaint and Punishment of SH at Workplace". From the entire legal system to specific regulations, they are clearly elaborated. Furthermore, sexually harassed victims extend from females to include both genders. Parties involved in SH can be of the same or different sexes.

In Moi University, the Sex Discrimination Policy was passed in 2010 which made SH unlawful under this law. SH can involve physical, visual, verbal or non-verbal conduct of a sexual nature which is uninvited and unwelcome. It also refers to a sexually hostile or intimidating environment for students in the educational setting which means any unwelcome sexual conduct that interferes with the performance or affects the enjoyment of students in their learning environment.

\subsubsection{How to Prevent Sexual Harassment in Campus}

The AAUW (2004) provided a resource guide "Harassment-Free Hallways" to help parents, students, institutions, and school districts. It includes: (1) Assess strengths and weaknesses with regard to existing SH policies; (2) Develop user-friendly SH policies based on existing models; (3) Stakeholders understand their respective rights and responsibilities for reporting and responding to reports of sexual harassment; and (4) Develop an attitude of leadership on the issue of SH in institution.

In 2008, the term "sexual harassment" was extended locally to cover conduct of a sexual nature which creates a hostile or intimidating environment in educational settings. TheEOC assisted the Education Bureau to develop "Questions and Answers on Preventing SH in Institution" which was then issued as guidelines to all primary and secondary institution. The EOC has played an important role in the prevention of SH in campus via different promotion and educational channels such as TV docu-drama series/ forum/ training/ teaching materials.

\subsection{Introduction}

\section{METHODOLOGY}

This chapter presents: study design, study area, population, data collection method and tools.

\subsubsection{Study design}

This study adopted a purposive descriptive research design involving 100 University of Eldoret students (First and Second years) whose data was collected using questionnaires and interview schedules.

\subsubsection{Study area}

The study was done at University of Eldoret which is based in Eldoret town, Uasin Gishu County, Kenya located 7 kilometres from Eldoret town North-Eastern part of Uasin Gishu along Eldoret-Ziwa - Cherangany road. The university comprises School of Sciences, School of Economics, School of Engineering, School of Natural Resource Management and School of Education Arts. 


\subsubsection{Target population}

The study involved 100 University of Eldoret students (First and Second years) drawn from School of Sciences, School of Economics, School of Engineering, School of Natural Resource Management and School of Education Arts.

\subsubsection{Data Collection Procedures}

The study adopted questionnaires and interview schedules that were administered to the respondents. Clarifications were made where necessary and respondents were assured of data confidentially. The researcher sought Permission to conduct this study from the Dean of Students of UoE and also from Heads of Departments involved in this study.

\subsubsection{Data Analysis}

The data collected during the research was coded accordingly to facilitate analysis. The coded data in Excel Spread Sheet was carried out using the statistical package for social science (SPSS) for analysis.

\section{RESULTS}

A total of 100 completed questionnaires were collected (Table 3.1 Figure 3.1).

Table 3.1 Number of students who participated in the questionnaire survey

\begin{tabular}{|l|l|}
\hline Participants & Number \\
\hline School of Sciences & 5 \\
\hline School of Economics & 12 \\
\hline School of Engineering & 10 \\
\hline School of environmental studies & 53 \\
\hline School of Natural Resource Management & 20 \\
\hline \multicolumn{1}{|c|}{ Total } & 100 \\
\hline
\end{tabular}

Profile of the Respondents

\section{NUMBER OF STUDENTS}

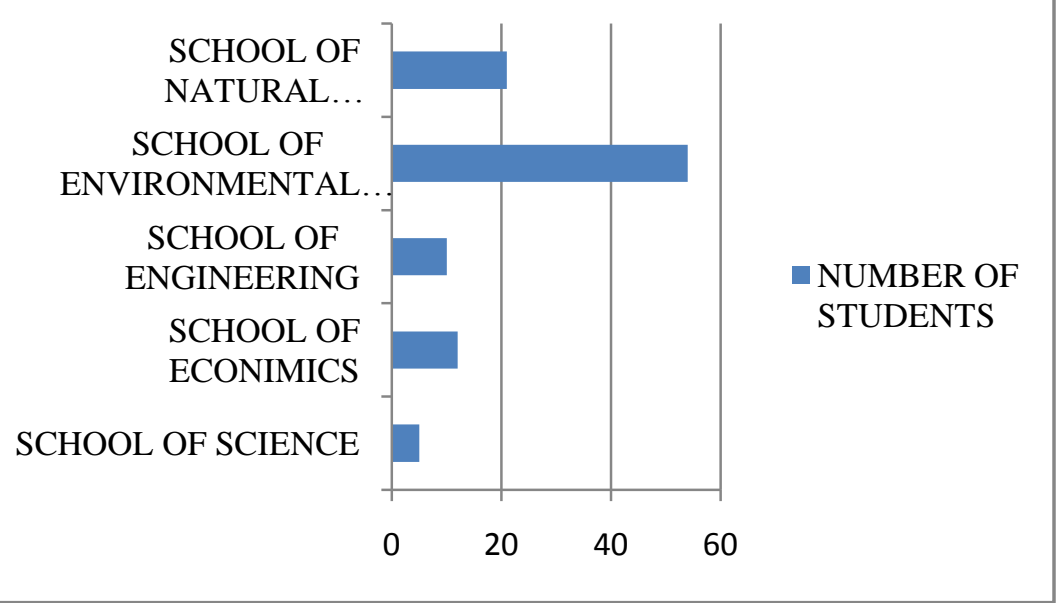

Figure 3.1 showing profile of the respondents

The responses by gender were as shown on table 3.2 below.

Table 3.2 Gender of the respondents

\begin{tabular}{|l|l|l|}
\hline Gender & No. of respondents & Percentage \\
\hline Male & 51 & $51 \%$ \\
\hline Female & 49 & $49 \%$ \\
\hline Total & $\mathbf{1 0 0}$ & $\mathbf{1 0 0 \%}$ \\
\hline
\end{tabular}




\section{Gender of respondents}

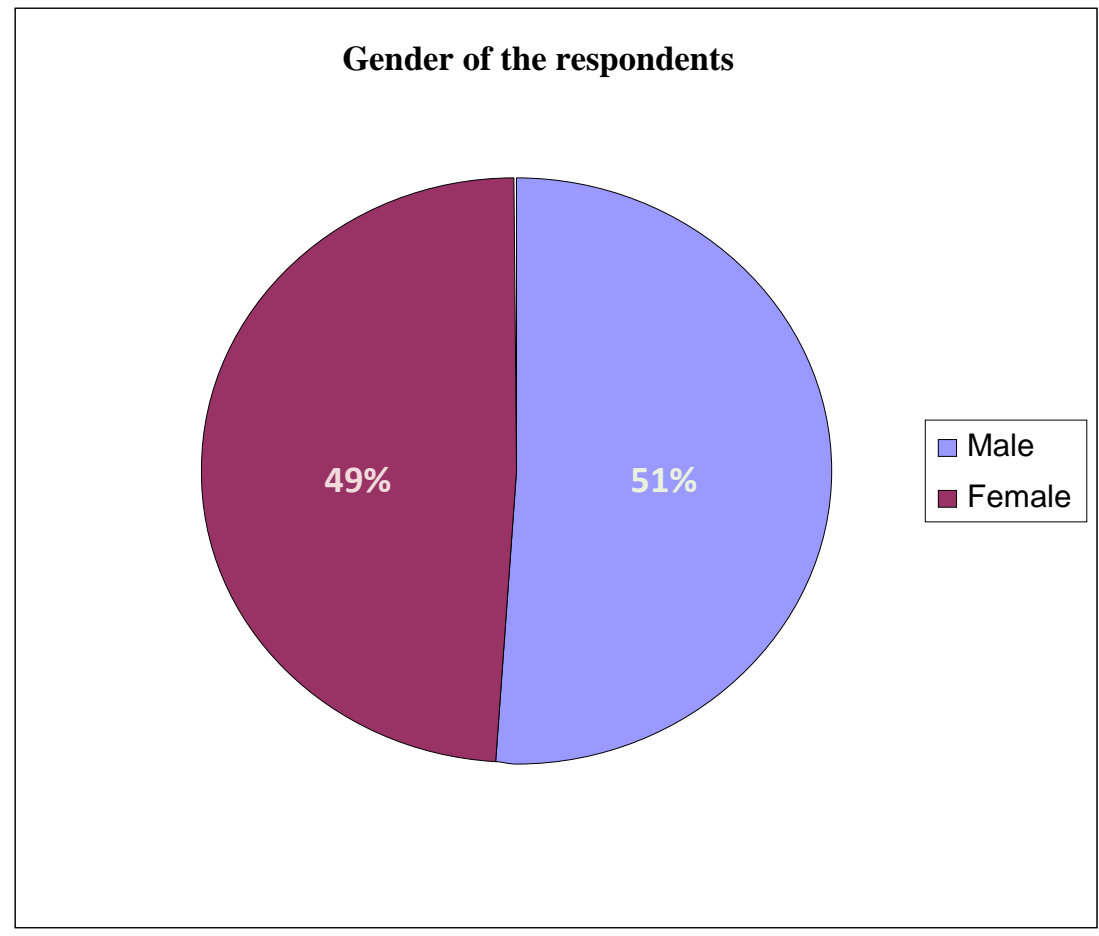

Figure 3.2 Gender of the respondent

From the study $51 \%$ of the respondents are male while $49 \%$ are females.

The research study also sought to find out the year of study of the respondents who participated in the study. Table 3.3 shows the responses as follows:-

Table 3.3 Year of study of the respondents

\begin{tabular}{|l|c|c|}
\hline Year of study & Frequency & \% \\
\hline First Year & 70 & 70 \\
\hline Second Year & 30 & 30 \\
\hline Total & 100 & 100.0 \\
\hline
\end{tabular}

The study findings indicated that most $70(70 \%)$ of the respondents were first years while another $30(30 \%)$ were second years. From these findings it is realized that most of the respondents were first years.

\section{Level of sexual harassment among university students within the institution.}

On questionnaire administered, students generally considered sexual behaviours in the questionnaire as sexual harassment. Among those physical sexual behaviours such as pulling clothing or touching others' body, $80 \%$ of the students reveal that they amount to sexual harassment. For those involving verbal sexual behaviours such as calling others 'gay' or 'tomboy', relatively fewer students (about 40\%) regard them as sexual harassment. In general, more female students than male students consider sexual behaviours in the questionnaire as sexual harassment. When compared to children and teenagers (their views are similar), more adults perceive sexual behaviours in the questionnaire as sexual harassment. Similarly, when compared to primary and secondary school students (their views are common), more university students regard sexual behaviours in the questionnaire as sexual harassment.

Knowledge and experiences of any form of sexual harassment among university students within University of Eldoret.

During the past one year, $50 \%$ of the students have experienced various forms of sexual harassment. Among them, most students indicate the experiences of "Someone made sexual jokes about you", "Someone talked about sex all the time in your presence", "Someone asked you to talk about sexual topics or to have intimate body contacts with the same/opposite sex", "Someone continuously made suggestions, propositions, or 
demands to you for sexual favours or sexual relationship" and "Someone rubbed or touched against you on purpose".

Sexual harassment, in terms of the forms, involves people of opposite sexes, of same sex and in a group. Among female students, who had been sexually harassed, they experienced "A male bothered by asking for dates, though you had answered "no", "A male continuously made suggestions, propositions, or demands to you for sexual favours or sexual relationship", and "A male rubbed or touched against you on purpose". Among male students, who had been sexually harassed, they experienced "Two or more males talked about sex all the time in your presence". Moreover, "Someone made sexual jokes about you" mostly occurred in social groups (two or more persons of both genders). Among students who have experienced sexual harassment, $97 \%$ of the victims express that the harassers are their "boy/girl friends". Next are "classmates" (21\%) and "friends" (14\%). SH primarily occurs in UoE (49\%). Most of the incidents take place "in the classroom" (25\%). It is followed by "in the hostels" (11\%) or "on public trips in institution vehicles" $(8 \%)$

More male students than female students express that they have experienced SH such as "Someone called you "gay", "Someone made sexual gestures/movements to you" and "Someone showed or passed to you pornography". More students than staffs and senior employees indicate that they have experienced SH of various forms. Similarly, more senior university students show that they have experienced various forms of sexual harassment, when compared to others and University students. Examples are "Someone made sexual jokes about you"; "Someone talked about sex all the time in your presence" and "Someone rubbed or touched against you on purpose".

\section{Perception and attitude of university management and students towards students' sexual harassment. Attitude of university management}

All organizations are concerned with what should be done to achieve sustained high levels of performance through education. The findings of the questionnaires indicate that the policies on SH mainly focus on the relationship between students and teaching staff/ external tutors. SH between students is seldom addressed. Both teachers and social workers consider that institution address the issue in a low-key manner in order to uphold their reputation. The general attitude is "don't make a mountain out of a molehill". It should be understood that not dealing with SH does not mean its disappearance. Indeed, effective ways of dealing with SH involve the collaboration of the Government, principals and teaching staff, parents, students and stakeholders in the community. As such, students can follow formal complaint procedures or legal means to solve the $\mathrm{SH}$ problems so that sexual harassers should receive appropriate punishment and counselling.

\section{Perceptions, experiences and Attitude of Students at University of Eldoret}

A questionnaire survey on the level of sexual harassment in University of Eldoret found that, among the 100 students who participated, nearly half of the respondents (48\%) expressed that no one had ever discussed with them about the phenomenon. More than $40 \%$ of the respondents believed that sexual harassment is different from sex services. The differences included that sexual harassment "may not involve sex", "can say no", "is more superior" and "have interflow of affection". More than one-third of the respondents had considered engaging in sexual harassment, of whom 55\% were males and over $70 \%$ clearly knew that it would have adverse impacts on the society. Their perceived key impacts were decline in morality (72\%), prevalence of sexually transmitted diseases $(69 \%)$ and distortion of monetary concept $(57 \%)$. This reflected that although students had the cognition of morality, they still would not give up the intention of engaging in sex.

Students generally consider sexual behaviours in the questionnaire as sexual harassment. Among those who considered SH as physical i.e. behaviours such as pulling clothing or touching others' body, $80 \%$ of the students reveal that they amount to sexual harassment. For those involving verbal sexual behaviours such as calling others 'gay' or 'tomboy', relatively fewer students (about 40\%) regard them as sexual harassment. In general, more female students than male students consider sexual behaviours as sexual harassment. Sexual harassment, in terms of the forms, involves people of opposite sexes, of same sex and in a group. Among female students, who had been sexually harassed, they experienced "A male bothered by asking for dates, though you had answered "no", "A male continuously made suggestions, propositions, or demands to you for sexual favours or sexual relationship", and "A male rubbed or touched against you on purpose". Among male students, who had been sexually harassed, they experienced "Two or more males talked about sex all the time in your presence". Moreover, "Someone made sexual jokes about you" mostly occurred in social groups (two or more persons of both genders). Among students who have experienced sexual harassment, 97\% of the students express that the harassers are their "boy/girl friends". Next are "classmates" (21\%) and "friends" (14\%). Sexual harassment primarily occurs "in Institution" (UoE) (49\%), where students spend much time in studying. Most of the incidents take place "in the hostels," $(25 \%)$. It is followed by "in the street" $(11 \%)$ or "lecture halls" $(8 \%)$.

More male students than female students express that they have experienced sexual harassment such as "Someone called you "gay", "Someone made sexual gestures/movements to you" and "Someone showed or passed to you pornography". When the students encounter sexual harassment, most of them indicate "Feeling angry" (40\%), "Feeling afraid or scared" (38\%) and "Cannot relate well with others" (36\%). However, fewer students express that their daily life will be affected, such as "Sleep disturbances" (7\%) and "Eating disorders" $(10 \%)$. On one hand, more female students are 
affected psychologically and emotionally, when compared to male students. On the other hand, more male students than female students are affected in daily life and interpersonal relationship. Over a half of the sexually harassed students are found to "Keep silent" (58\%) and "Complain to the harassers" (51\%). They are followed by "Tell classmates/friends" (39\%) and "Call the police" (34\%). They seldom choose to seek help from "family members" (16\%), "seniors in school" (5\%) and "the EOC" $(3 \%) .53 \%$ of the students indicate that promotional materials such as posters/leaflets about preventing or dealing with sexual harassment should be posted or delivered in school. About a half of the students (51\%) express that there are no institution policy and regulations on prevention of sexual harassment. Apart from these, $44 \%$ of the students reveal that few school assemblies/seminars/workshops on prevention of sexual harassment are held. Students indicate that school assemblies/seminars/workshops on prevention of sexual harassment are delivered by lecturers (20\%), the EOC (18\%) and social service organizations outside school (17\%). The proportions of the latter two sources tend to be low. This reflects that institution is less likely to engage in external resources to promote the prevention of sexual harassment, and therefore, social workers and teachers in school have to bear greater responsibilities of educating the students.

\section{Effects of SH on students' academic performance at the institution.}

When the students encounter sexual harassment, most of them indicate "Feeling angry" (40\%), "Feeling afraid or scared" (38\%) and "Cannot relate well with others" (36\%). However, fewer students express that their daily life will be affected, such as "Sleep disturbances" (7\%) and "Eating disorders" (10\%). On one hand, more female students are affected psychologically and emotionally, when compared to male students. On the other hand, more male students than female students are affected in daily life and interpersonal relationship. They include "Cannot relate well with others", "Cannot study well" and "Eating disorders". Alternatively, more UoE students are obviously affected in some ways. They include "Feeling helpless", "Feeling angry" and "Feeling stressed and confused". The findings of focus group survey are supplementary to questionnaire survey data. First, there are discrepancies between how the students understand the definition of SH and their actual responses in real life situations. In the course of determining whether certain behaviours are actually sexual harassment, the students are more concerned about the motives and mentality of the perpetrators. Since most incidents of sexual Harassment involves friends or classmates, the victims find that it is somewhat difficult to differentiate the harassers' intention. There are times when the students even think that the behaviours form part of the school ethos or a playful culture, with verbal SH in particular. Students indicate that the current education on SH is inadequate, and its importance has not been emphasized in UoE. UoE curricula are so compacted that prevention of $\mathrm{SH}$ as well as sex education is not included. The students hope that training courses about sex education will be provided so that they have the opportunities to learn how to nurture them about sexual harassment. Some of the students express that UoE tend to handle complaints of SH in a very subtle manner (or even doing nothing), fearing that the institution's reputation would be adversely affected.

\section{SUMMARY OF FINDINGS AND DISCUSSION}

University of Eldoret has no policy that addresses issues related to sexual harassment. The occurrence of sexual harassment originates from the harassers, who have discriminated against the victims by violating their rights physiologically, sexually and physically. The mild cases cover rude sexual jokes, showing/ passing pornographic materials, indecent gestures, attitudes, behaviours, insults and touches. The moderate cases include continuous propositions or demands against students' willingness. The serious cases consist of sexual assaults or attacks. This study reveals that about a half of the interviewed students have experienced various forms of sexual harassment without their consent. Furthermore, over one-third of the second year students indicate that they have been sexually harassed (mainly on sexual jokes) in the previous year. First year students have experienced sexual harassment from day one in the school (e.g., sexual topics or jokes, propositions or demands to view pornographic videos/ webpages / publications). This shows that there has not been much improvement in reducing sexual harassment in UoE. It is worrying that during the focus group discussion sessions, some students have accepted sexual harassment as institution's culture. Therefore, although other students have expressed resentment, sexual harassment will still go on.

In the face of sexual harassment, most of the students react passively by addressing the issue on their own. For example, they will choose to tolerate or to leave. Even though the harassers are mostly students, the students rarely seek help from the institution. Some students think that their tutors, either embarrassed or inexperienced, are incapable of handling cases of sexual harassment. The fear of revenge also prevents them from reporting the incidents of sexual harassment to their teachers. It is rare for the students to seek external assistance and therefore they are alone to face the incidents. Despite the fact that they can talk to family members or friends and get reliefs from fearful and angry emotions, their negative feelings from embarrassment to damage of self-respect, and even depression linger. Local studies point out that victims, after being sexually harassed, show low self-confidence/ self-image, depression, insecurity, and poor sense of belongingness to school. Overseas research shows that apart from feeling unsafe at school, elevated risk of suicidal thoughts, early dating and substance use are also found. 
The findings of the focus group survey indicate that the policies on sexual harassment mainly focus on the relationship between students and teaching staff/ external tutors. Sexual harassment between students is seldom addressed. Both teachers and social workers consider that institution address the issue in a low-key manner in order to uphold their reputation. The general attitude is "don't make a mountain out of a molehill". It should be understood that not dealing with sexual harassment does not mean its disappearance. Indeed, effective ways of dealing with sexual harassment involve the collaboration of the Government, principals and teaching staff, parents, students and stakeholders in the community. As such, victims can follow formal complaint procedures or legal means to solve the sexual harassment problems so that sexual harassers should receive appropriate punishment and counselling.

Based on the above discussions, there are a number of areas that need improvement in terms of the preventive measures against sexual harassment on campus and proper management in handling complaints of sexual harassment. In this regard, the following are proposed recommendations:

\section{Recommendations}

University Of Eldoret should develop a policy to address sexual harassment. This policy should give a clear definition on SH so that principals, teaching staff and social workers know how to handle SH cases. The system of complaint-handling should serve to safeguard the basic rights of tutors and students, as well as their gender equity and equality. In operation, the system should uphold the principles of fairness, transparency and protection of privacy, and the authority to discipline.

With reference to the universities, mechanisms should be established in order to handle complaint cases. Concurrently, all students should understand clearly about the complaint procedures (e.g., relevant information uploaded on the school website). Moreover, appropriate channels should be provided for students who can seek help in confidence. Once the policy is set, UoE should enforce the policy, with proper mechanism to monitor the implementation and review the policy from time to time, in order to ensure the efficacies of its implementation.

\section{References}

[1]. AAUW Educational Foundation (2001). Hostile hallways: Bullying, teasing, and SH in school.

[2]. AAUW Educational Foundation (2004). Harassment-Free Hallways: How to Stop SH in School.

[3]. AAUW Educational Foundation (2005). Drawing the Line: SH on campus.

[4]. AAUW Educational Foundation (2011). Crossing the Line: SH at school.

[5]. Chaffin, S. M. (2008). The new playground bullies of cyberspace: Online peer sexual harassment. Howard Law Journal, 51, 773818 .

[6]. Chiodo, D., Wolfe, D. A., Crooks, C., Hughes, R., \& Jaffe, P. (2009). Impact of SH victimization by peers on subsequent adolescent victimization and adjustment: a longitudinal study. Journal of Adolescent Health, 45(3), 246-52.

[7]. Connell, R. W. (1987). Gender and Power: Society, the Person and Sexual Politics. Stanford: Stanford University Press.

[8]. Connell, R. W. (1992). A Very Straight Gay: Masculinity, Homosexual Experience, and the Dynamics of Gender. American Sociological Review, 57, 735-751.

[9]. Connell, R. W. (2002). Gender. Cambridge: Polity Press.

[10]. Cronbach, L. J. (1951). Coefficient alpha and the internal structure of tests.Psychometrika 16, 297-334

[11]. Dellinger, K., \& Williams, C. (2002). The locker room and the dorm room: Workplace norms and the boundaries of SH in magazine editing. Social Problems, 49, 242-257.

[12]. Leaper, C., \& Brown, C. S. (2008).Perceived experiences with sexism among adolescent girls.Child Development, 79(3), 685-704.

[13]. Lee, N. Y. (1999). Sexual harassment at Campuses and Regulations.Journals for Women's Study, 10, 163-174.Silla University,

[14]. Linacre, J. M. (1994). Sample size and item calibration stability. Rasch Measurement Transactions, 7(4), 328.

[15]. Margolis, J. (1993, July 6). The figures can lie and the lies can figure. Chicago Tribune, Perspective, p. 17

[16]. Ministry of Gender Equality and Family (2002).Reports on sexual harassment at university campuses in Korea.

[17]. Pepler, D. J., Craig, W. M., Connolly, J. A., Yuile, A., McMaster, L., \& Jiang, D. (2006). A developmental perspective on bullying.AggressiveBehavior, 32, 376-84.

[18]. Petersen, J. L., \& Hyde, J. S. (2009).A longitudinal investigation of peer sexual harassment victimization in adolescence.Journal of Adolescence, 32(5), 1173-88.

[19]. Roberts, D. F., \&Foehr, U. G. (2008).Trends in Media Use.Children and Electronic Media, 18(1), 11-37.

[20]. Shariff, S., \& Strong-Wilson, T. (2005). Bullying and new technologies: What can teachers do to foster socially responsible discourse in the physical and virtual school environments? In J. L. Kincheloe (Ed.), Classroom teaching: An introduction (pp. 21940). New York, NY: Peter Lang.

[21]. Shoop, R. J., \& Edwards, D. L. (1994).How to stop sexual harassment in our schools. Boston: Allyn\& Bacon.

[22]. Shoop, R. J., \&Hayhow, Jr., J. W. (1994). Sexual harassment in our schools: What parents and teachers need to know to spot it and stop it. Boston, MA: Allyn\& Bacon.

[23]. Timmerman, G. (2005). A comparison between girls' and boys' experiences of unwanted sexual behavior in secondary schools.Educational Research, 47(3): 291-306.

[24]. Tokunaga, R. S. (2010). Following you home from school: A critical review and synthesis of research on cyberbullyingvictimization.Computers in Human Behavior, 26, 277-87.

[25]. Walsh, M. Duffy, J., \& Gallagher-Duffy, J. (2007).A more accurate approach to measuring the prevalence of sexual harassment among high school students.Canadian Journal of Behavioral Science, 39(2), 110-118. 74

[26]. Williams, C. L., Giuffre, P. A., \& Dellinger, D. (1999). Sexuality in workplace: Organizational control, sexual harassment and the pursuit of pleasure. Annual Review of Sociology, 25, 73-93.

[27]. Young, A. M., Grey, M., \& Boyd, C. J. (2008). Adolescents' experiences of sexual assault by peers: Prevalence and nature of victimization occurring within and outside of school. Journal of Youth and Adolescence, 38(8), 1072-83. 